\title{
Roy Wagner e a fractalidade: considerações sobre $o$ gesto êmico
}

Iracema Dulley (LSE/Cebrap)
E, todavia, esses mesmíssimos intérpretes, como todos os xamãs, também estão sujeitos aos caprichos de seus espíritos familiares.

Roy Wagner, $A$ invenção da cultura

Em "A pessoa fractal", Roy Wagner (2011a) estabelece uma oposição entre o big man, que remeteria à concepção de liderança ocidental, e o great man, descrição da liderança melanésia com base na proposta de fractalidade apresentada pelo autor. Acompanho a seguir o movimento wagneriano de deslocamento da ideia do big man em defesa de uma concepção de great man, a qual é relacionada a concepções sobre nomeação e moeda na Melanésia e apresentada como mais próxima do que seria a visão melanésia sobre a socialidade ${ }^{1}$. Meu percurso pelo texto de Wagner tem dois objetivos: acompanhar os efeitos que a subscrição wagneriana ao gesto êmico gera em sua descrição e contribuir para o trabalho de deslocamento das categorias de nomeação na antropologia. Detenho-me especificamente sobre a afirmação wagneriana recorrente de que o todo é um e portanto, quando dividido, segmenta-se apenas em hologramas de si mesmo. Meu engajamento com a fractalidade wagneriana pretende mostrar como, para aceitar o suposto da autorreplicação fractal e da instanciação do mesmo, seria preciso abrir mão da diferença. ${ }^{2}$

\section{OS NOMES, UM GESTO}

Entendo por gesto êmico o gesto antropológico clássico que consiste na designação da alteridade por meio de nomes que em última instância indicam pertencimento a um grupo ou categoria com maior ou menor grau de delimitação. O gesto em questão não é, obviamente, característica exclusiva 
de Roy Wagner. Ele pode ser - e é com frequência - encontrado em uma miríade de autores, de Boas a LéviStrauss, de Clastres a Geertz. A despeito da diversidade de abordagens, esses autores nomeiam de forma semelhante aqueles que apreendem como outros - e, de forma complementar, aqueles que concebem como semelhantes a si. Em Wagner, exemplos de nomes desse tipo são "Daribi", "Barok", "melanésio", "tribal", "ocidental", "americano". Embora não seja minha intenção atribuir esse gesto a Wagner em particular, discutir a questão a partir de sua obra parece-me profícuo porque o autor não só realiza uma reflexão teórica sobre a nomeação como explicita a posição epistemológica que fundamenta sua abordagem: uma defesa simultaneamente ética e teórica do êmico (cf. Wagner 2010a).

Pretendo, assim, partir deste caso particular, interessante porque explícito e sistemático na defesa de seu partido, para pensar uma forma de nomeação que fundamenta o próprio exercício antropológico. Meu objetivo, ao final deste exercício, não é apresentar um apanhado geral das formas de nomeação em antropologia, nem propor a melhor solução para a questão dos nomes e da categorização na disciplina, ou tampouco desautorizar formas de nomear que no limite estão colocadas pela própria linguagem. Meu intuito é, antes, contribuir para o trabalho de deslocamento e desestabilização das categorias de nomeação na disciplina ao mostrar como uma certa abordagem da questão da nomeação geralmente se vincula a certa concepção da diferença. O objetivo deste exercício não é uma oposição frontal à ideia de alteridade, mas uma tentativa de rasurá-la.

Em 1991, no artigo "A pessoa fractal" (doravante FP), sobre o conceito melanésio de pessoa, Roy Wagner (2011a) relaciona a fractalidade às práticas de nomeação daribi. FP estabelece uma oposição entre as concepções de big man e great man na Melanésia, sendo que os primeiros operariam, de acordo com Wagner, uma mudança de escala da dimensão do indivíduo para a dimensão do grupo, sendo "forças sociais mobilizadoras", ao passo que os segundos, pensados pelo autor em contraposição às teorias sociológicas vigentes ${ }^{3}$, estariam vinculados a uma totalidade ou socialidade preexistente, marcada por uma concepção fractal da pessoa ${ }^{4}$, o que faria com que seu lugar social de great men fosse ocupado na medida em que eles mantivessem uma relação de fractalidade com as outras pessoas, ou seja, não exercessem sobre elas poder coercitivo. Nesse modelo, proposto como alternativa à concepção de indivíduo e grupo do estruturalfuncionalismo e do estruturalismo ${ }^{5}$, as relações que a pessoa estabelece com os outros são parte constituinte de si: há continuidade entre dentro e fora. Ademais, ela reproduz, em qualquer grau de ampliação, apenas versões de si mesma, ou seja, "mantém sua escala".

O artigo em questão é um importante ponto de virada na teoria wagneriana, que a partir dos anos 1990 desviará o foco da dialética entre convenção e invenção proposta n'A invenção da cultura (Wagner 2010b, doravante TIC) para voltar-se à construção de um modelo no qual não haja distinção entre parte e todo, que o autor afirma ter sido concebido a partir do modo de simbolização melanésio. A "pessoa fractal" 
parece estar a meio caminho entre o modo de simbolização diferenciante (atribuído aos "povos tribais"7) e a automodelagem (Wagner 2001a, 2012). Mas apesar desse deslocamento teórico, o pensamento de Wagner permanece atrelado ao que denomina dialética: tudo se passa como se o novo movimento, de repensar a antropologia a partir da Melanésia, realizasse uma generalização - modo de simbolização pertinente ao Ocidente por excelência - a partir do modo de simbolização melanésio - diferenciante. Seu recurso à simbolização do outro teria, pois, se bem-sucedido, o efeito de generalizar a generalização da holografia e da fractalidade a partir de uma solução holista para a disjunção entre generalização e particularização em antropologia. Sigamos seu argumento.

\section{POAI, FRACTALIDADE E TOTALIZAÇÃO}

A oposição entre indivíduo e sociedade, para Wagner, "coincide com a hegemonia do pensamento 'social'" porque é idêntica a ele. Os conceitos de indivíduo e sociedade são por ele rejeitados por privilegiarem um aspecto ("ocidental") da realidade em detrimento de outras perspectivas possíveis. O "conceito de social" é considerado pelo autor como "ideal e praticamente irrealizável", e a pessoa como objeto, como “necessariamente física, material e substantiva" (Wagner 2011a: 2). O "grupo" de indivíduos é, pois, visto pelo autor como produto do fracasso do ideal de corporatividade, ou seja, da fusão de diversos indivíduos em um único corpo: "[e] a noção de uma 'cultura' de representação coletiva totalmente integrada no interior do indivíduo [suposta por esse ideal de corporatividade] torna-se, ao fracassar em sua realização, um mero 'conceito-de-cultura', um ideal" (Wagner 2011a: 2). A cultura que Wagner busca parece, portanto, ser real em oposição a ideal. Em seu pragmatismo, ele se opõe à ideia de cultura como ideal porque ela não é plenamente realizável nos indivíduos devido a seu caráter de representação:

A questão não é simplesmente que uma oposição equivocada e realista entre pensamento e substância reproduzse como um fato social mensurável, que os grupos sociais e as culturas idealizadas são produzidos em massa como um mapa de variação e problemática sociocultural. (...) [A] questão é que uma dependência ingenuamente hegemônica em relação à individualidade e à pluralidade subjaz à - e articula $\mathrm{a}$ - maneira como o conceito idealizado e o objeto substantivo são colocados em relação (Wagner 2011a: 2-3).

Aqui fica clara a oposição do autor à separação entre pensamento e substância. Seu esforço parece ser o de estabelecer uma ponte entre o universo da linguagem e o universo das coisas. A perspectiva êmica é, de certa forma, apresentada como uma maneira de chegar à coisa em si: o pensamento nativo não só revelaria os vieses do pensamento ocidental, como também, na qualidade de instanciação da fractalidade do cosmos, permitiria chegar à matriz da unidade que se replica no todo. É como se as culturas fossem um fractal do humano, que seria por sua vez um fractal do cosmos. Somos, pois, reconduzidos ao pensamento nativo, que daria a ver o que o pensamento ocidental ignora: 
Assim, enunciar uma proposição como "nenhuma sociedade funciona de forma perfeita", ou mesmo "a razão pela qual nenhuma sociedade funciona de forma perfeita é que seus membros esperam que ela o faça" é descrever as expectativas dos próprios antropólogos, e não as de seus sujeitos de pesquisa. Pois o que é descrito é a maneira como os cientistas sociais operam para tornar seus sujeitos interessantes, estatisticamente variáveis e problemáticos. Não está de modo algum claro que os sujeitos pensam sobre si mesmos dessa maneira, ou que pensam que suas interações sociais são interessantes porque podem ser mapeadas em paradigmas de agrupamentos sociais e variabilidade individual (Wagner 2011a: 3).

A ideia do mecanismo social, segundo Wagner, não existia "de forma nativa" na Melanésia, mas foi levada para lá por "indivíduos' autoconscientes" (Wagner 2011a: 3 - notem-se as aspas em "indivíduos". A nomeação, aqui, aponta para as origens, quando essa noção não existia: ela teria sido levada por esses "indivíduos" ocidentais. A defesa de que existe um pensamento nativo precisa, portanto, da ideia de um antes que se contraponha ao momento atual, inegavelmente pós-contato, para que se possa traçar uma distinção clara entre o pensamento melanésio (em Wagner, instanciado ora pelos Daribi, ora pelos Barok, ora pelos melanésios) e o pensamento ocidental.

Wagner sugere que, "ao menos para alguns melanésios" (Wagner 2011a: 3), o holismo está além e aquém da distinção geral/particular e indivíduo/sociedade em sua instanciação holográfico-fractal. Ou seja, a distinção parte/todo e suas implicações sistemáticas seriam inaplicáveis ao contexto melanésio. O holismo, aqui, é da ordem do porquê, e não do como, sendo este último criticado por Wagner por "não leva[r] a uma revisão completa de nossos supostos", mas procurar na particularidade dos melanésios um universal que seria, em última instância, o "nosso". Ora, os melanésios e sua forma de pensamento são apresentados pelo autor como uma descoberta que nos permitiria chegar ao porquê ao ultrapassarmos nosso próprio como, em um movimento que coloca a antropologia como "etnografia da filosofia" (Wagner 2011b). Entretanto, o aposto, embora passe quase despercebido, é muito interessante: "ao menos para alguns melanésios". A mesma expressão é usada quando Wagner se refere ao ciclo de plantio "tradicional" dos Barok, ainda que entre estes, reconhecidamente mais afetados pelo "contato", ele faça a ressalva de que isso ocorre de forma anedótica: "Ao menos para alguns Usen Barok, o céu ainda serve de modelo ao ciclo de plantio, ainda que de forma anedótica" (Wagner 1986b: 43, ênfases minhas).

O motivo pelo qual não se pode, em Wagner, generalizar essa afirmação para todos os "melanésios" é o fato de o Ocidente já ter se feito presente no Pacífico. A afirmação de que isso ocorre "ao menos para alguns melanésios" parece entrar em choque com sua recusa em tratar da relação entre teoria e empiria pela via da generalização/particularização. É como se, dada sua opção pela totalização do outro sob diversos nomes (melanésio, Daribi, Barok), a afirmação de que a totalização é válida, ainda que não esgote esses "outros", bastasse para pôr fim à questão da generalização, ou seja, de como passar da particularidade, "barok" ou "melanésia", para a suposição da fractalidade como modo de operação não só do humano, mas do "tecido da congruência universal" (Wagner 2001a: 6), ou seja, de todo o cosmos. Isso parece especialmente digno de nota se levarmos em conta sua densa discussão a respeito da dialética entre generalização e particularização (Wagner 1977b): o produto dessa dialética seria uma negociação, por parte da ciência, do 
paradoxo da unidade e da relação, da qual uma instanciação seria a dialética entre cultura e comunicação na antropologia.

Houvesse o aposto passado despercebido, escorregaríamos facilmente do modelo construído em relação com sua etnografia para a realidade "dos Daribi", "dos Barok" ou "dos melanésios", como a forma de nomeação adotada levaria a crer. Supondo que "ao menos alguns melanésios" pré-contato simbolizassem dessa forma e pudessem ser tomados como instanciação da fractalidade, resta a pergunta, não abordada pelo autor, sobre o que fazer com os outros melanésios, pré ou pós-contato, que possivelmente simbolizariam de outra forma, colocando em risco a fractalidade proposta, uma vez que ela não pode prescindir da igualdade no interior da diferença. Dito de outro modo, o que fazer com a diferença no interior da diferença?

Em sua teorização sobre a fractalidade da pessoa melanésia, Wagner contrapõe-se à ideia de atrito, definido, em física, como a componente horizontal da força de contato resultante do choque entre dois corpos distintos:

Um motor sem partes móveis ao menos evita a nêmese do atrito. E o atrito bem pode ser o efeito que os cientistas sociais erroneamente tomam como vantagem social. (...) Ou ao menos é isso que a concepção de big man que nos chega sugeriria: um imperador do atrito social que usa a sociedade contra ela mesma para restaurar o indivíduo essencial ao ápice (Wagner 2011a: 3).

Wagner afirma, pois, que o great man não é utilitarista e não se vale do atrito social para conquistar e manter sua posição. Ele é um ser cultural que trabalha em prol de sua cultura porque faz parte dela assim como ela faz parte dele - holográfica e fractalmente. A equivalência entre o nome e a coisa é, pois, reiterada a despeito do aposto acima, de modo que seja possível manter a divisão entre "nós" e "eles" com o intuito de atribuir a "eles" uma solução para um problema que verificamos em "nós". Nas palavras de Wagner, "[o] maior desafio consiste em chegar a um modo de pensamento mais holista do que aquele implicado pela estrutura, e o great man é sua contraparte holista" (Wagner 2011a: 3).

O great man é preferível, portanto, por ser um substituto "mais holista" do que a estrutura, ou seja, vem suplementá-la. No lugar da estrutura está, pois, a concepção nativa em sua teoria. Mas se levarmos adiante as implicações de seu pensamento, de que "os Daribi" seriam uma instanciação do humano, ou ainda, do cosmos, em que medida seria possível continuar falando em uma perspectiva nativa como garantidora da fractalidade que não opera mudança de escala? A fractalidade, levada às últimas consequências, não implicaria a abolição das fronteiras entre as "culturas", uma vez que sua replicação é sempre autorreplicação? Com isso, seriam abolidas não só a diferença cultural e suas totalizações, como a própria diferença no interior da diferença. Para a fractalidade holográfica holística de Wagner, todo e qualquer evento seria meramente uma replicação do "tecido da congruência universal" e, como tal, o mesmo com roupagens outras. Se isto for assim, a pessoa fractal não só contribui para subsumir a diferença no interior da igualdade, como a utiliza com um propósito tão autorreflexivo que qualquer tentativa de leitura de traços divergentes é engolfada pela autorreferencialidade. A passagem a seguir parece confirmá-lo: 
Será o big man [o] equivalente [do great man] em um outro tipo de sociedade, mais aberta, competitiva e frouxamente organizada? Ou será essa tipificação do big man ela mesma o erro de uma outra forma de abordar a sociedade, e portanto não um contraste tipológico, em absoluto? (Wagner 2011a: 3).

Para Wagner, a leitura do big man como "erro" acima prescinde de justificativa. Com base no posicionamento do autor em outros momentos, pode-se dizer que ela é desclassificada por ser da ordem do como e não do porquê. Entretanto, é curioso que as descrições de "outras" ordens de como nunca sejam expostas como "erros"; elas servem, antes, como contraposição à "nossa" ordem de como de modo a chegar ao que o autor entende como porquê. O big man seria característico de sociedades "abertas, competitivas e frouxamente organizadas", como a "nossa". A atribuição que subjaz a essa ideia, segundo a polarização pressuposta pela dialética wagneriana ${ }^{8}$, é de que as outras sociedades seriam fechadas, igualitárias e rigidamente organizadas. Como consequência dessa contraposição, as fronteiras sociais na Melanésia são enrijecidas - "ao menos [entre] alguns melanésios", os únicos dos quais a reflexão se ocupa. A armadilha é a própria pergunta colocada pelo autor: em sua adesão ao nome com o objetivo de chegar ao porquê, ele precisa postular a comparação com "um outro tipo de sociedade" (Wagner 2011a: 3). Ou seja, abre mão da visão holista de mundo ao atribuí-la a um segmento totalizado do todo. Interessantemente, a justificativa para sua posição a partir do nome "melanésio" será buscada nas formas de nomeação "daribi".

\section{OS NOMES E OS OUTROS}

Para Wagner, se o big man produz a sociedade, no caso do great man ela já está posta. Assim, na Melanésia, a sociedade e a solidariedade não só seriam pressupostas como não precisariam ser produzidas. Ora, a possibilidade de tal afirmação é, uma vez mais, garantida pelo nome do outro, que não só serve de fundamento para a diferença apontada, como coloca a necessidade de repensar os termos etnográficos de modo a garantir que mantenham uma relação de maior adequação com o universo empírico que se busca descrever. Afirma Wagner: “Então, é claro, os esforços do big man têm de ser reconsiderados ou renomeados; ele não está encenando a resposta a uma questão sociológica, pois esta já foi respondida" (Wagner 2011a: 4). Se o great man não produz a sociedade, como faz o big man, há que encontrar uma maneira de designá-lo que aponte para essa diferença. O nome deve, pois, ser substituído para se adequar à coisa. Nesse esforço de adequação, a ideia é fazer com que haja a menor distância possível entre o nome e a coisa nomeada. Ou seja, as coisas, em Wagner, independem dos nomes que recebem, muito embora os nomes sejam indispensáveis para a descrição - mesmo para falar de coisas que são "too definite for words" (Wagner 1986a).

Assim, pode-se dizer que sua antropologia é uma tentativa de traduzir essas coisas da forma mais fiel possível: uma tentativa de tradução que suprima a violência do deslocamento. $O$ indivíduo e o grupo são apresentados como alternativas falsas porque remetem à ideologia política ocidental e não refletem as práticas e conceitos desses outros. Na moka, os great men seriam igualmente válidos entre si, a despeito 
de quão bem-sucedidos fossem, pois nada produziriam: apenas realizariam algo que já estaria lá. Seria esta a diferença entre o big man e o great man: o primeiro produziria a sociedade, ao passo que o segundo seria uma parcela do grande fractal de pessoas que fazem com que ela aconteça. O great man atualizaria o que já estaria lá como potência; não criaria a sociedade. Ora, a única maneira de excluir a violência do político é afirmando que as ações políticas são simplesmente a atualização do que deve ser. Dessa forma, na perspectiva que se atribui ao outro, a sociedade não só está lá, como reitera a si mesma de forma fractal, e portanto não violenta, em todas as suas instanciações.

A pessoa fractal de Wagner, apropriação do conceito de pessoa melanésia de Strathern (1990), tomado emprestado da reflexão de Haraway (1985) sobre os ciborgues, é, segundo ele, uma "noção matemática de uma dimensionalidade que não pode ser expressa em números inteiros" (Wagner 2011a: 4), definida em contraposição à singularidade ou pluralidade (indivíduo ou sociedade), pois as aspirações do great man seriam ao mesmo tempo individuais e corporativas. Aqui, a questão clássica do singular e do plural, do indivíduo e da sociedade, é resolvida a partir do gesto que indica o ponto de vista do outro: para o outro, não há nem singular, nem plural. O singular e o plural dissolvem-se na fractalidade do um:

Uma pessoa fractal nunca é uma unidade em relação a um agregado, ou um agregado em relação a uma unidade, mas sempre uma entidade cujas relações estão integralmente implicadas. Talvez a ilustração mais concreta da relação integral venha da noção generalizada de reprodução e genealogia. As pessoas existem do ponto de vista reprodutivo ao serem "gestadas" como parte de outra pessoa, e "gestam" ou engendram outras ao se tornarem "fatores" genealógicos ou reprodutivos dessas outras. Uma genealogia é, pois, um encadeamento de pessoas, como, de fato, as pessoas seriam vistas "brotando" umas das outras em uma representação cinemática acelerada da vida humana (Wagner 2011a: 4).

O texto confirma a análise acima: enfatiza a reprodução e, com ela, a manutenção do mesmo. E a genealogia aponta para a origem: "A pessoa como ser humano e a pessoa como linhagem ou clã são igualmente seccionamentos ou identificações arbitrários desse encadeamento, diferentes projeções de sua fractalidade" (Wagner 2011a: 4). Se tudo está interligado, qualquer corte é arbitrário. A fractalidade não só conecta, como unifica:

Mas disso decorre que o encadeamento por meio da reprodução corporal é, ele mesmo, apenas uma entre as inúmeras instanciações ${ }^{9}$ da relação integral, que também se manifesta, por exemplo, no caráter comum da linguagem compartilhada (Wagner 2011a: 4).

Aqui fica claro o lugar da linguagem na teoria de Wagner: ela é uma instanciação da relação integral, que é holográfica e fractal. Na modalidade fractal, a comunicação é necessariamente entendimento. Nela, a linguagem não exatamente produz o mundo; ela é uma das formas de manifestação de um modo de ser do qual é inseparável. O fractal não produz; replica o mesmo.

A questão [da pessoa fractal] requer evidências, e a melhor evidência em que consigo pensar vem do modo como os melanésios, de forma nativa, exprimem, ordenam e conceitualizam a existência como identidade (Wagner 2011a: 5). 
A existência, para essa diferença que se encontra sob o nome "melanésios", é, pois, identidade. Ao olhar para a diferença para encontrar a identidade, Wagner apóia-se na forma de nomeação do outro:

Essa nomeação [entitlement] da existência é, muito simplesmente, aquela da nominação [naming], pois afinal são os nomes, e não os indivíduos ou os grupos, que "ascendem" na moka, que suscitam reverência, atenção e responsabilidade no Kula, que servem, como "grandes" ou "pequenos", às identidades daquilo que estamos predispostos a chamar de grupos - linhagens, clãs ou o que quer que seja. A despeito da amplitude de sua denominação, seja ela pessoal ou coletiva, nomes são apenas nomes; mas se trata de um nome que é ao mesmo tempo a aspiração individual e coletiva dos big men. Um amigo daribi uma vez observou: "Quando se vê um homem, ele é pequeno; quando se diz seu nome, ele é grande" (Wagner 2011a: 5).

Aqui, o gesto êmico, a partir do qual se afirma que os nativos lidam com a existência como identidade, atrela-se explicitamente à forma nativa de nomeação: são os nomes, e não os indivíduos ou grupos, que ascendem na moka. Eles servem às identidades do que "estamos predispostos a chamar de grupos" (cf. Wagner 2010a) - há, portanto, algo, e esse algo recebe denominações diversas, entre as quais a "melanésia" seria mais próxima da coisa do que a "ocidental". Os nomes são apenas nomes, mas refletem a aspiração do big man, que é ao mesmo tempo individual e coletiva. É a perspectiva "melanésia", pois, que serve de caução à tentativa de suprimir a diferença entre o nome e a coisa, já apresentada em TIC como tendência do pensamento diferenciante. É na perspectiva "melanésia" que essa identidade é possível, pois eles "lidam com a existência como identidade". A partir desse deslocamento, pode-se lidar legitimamente com a diferença no interior da diferença como identidade - como fariam "os melanésios", para quem supostamente a replicação, sendo fractal, prescindiria de diferença, e portanto de lidar com a violência (por exemplo, a que caracteriza o deslocamento entre nome e coisa).

Wagner segue: "O exemplo que utilizarei é o da nominação [naming] daribi. Um nome daribi, nogi, é sempre uma instanciação, e também uma simplificação, da relação designada pelo particípio, poai, do verbo poie, 'ser congruente com'" (Wagner 2011a: 5). O nome é exemplo, instanciação, porque a linguagem é, para Wagner, uma manifestação da fractalidade; e como nome, e não coisa, necessariamente perde em substância:

Duas pessoas, ou uma pessoa e uma coisa, que partilham o mesmo nome são tedeli nogi poai, "congruentes por um nome". Dois seres que partilham o mesmo tipo de pele são tedeli tigi ware poae, "congruentes por uma epiderme". Qualquer coisa que possa ser designada por uma palavra está em relação de poai por meio de qualquer ponto de semelhança concebível. Ademais, quaisquer duas pessoas ou dois objetos que partilhem, cada qual por sua vez, qualquer ponto de semelhança concebível com um terceiro, estão relacionados como poai por meio desse terceiro. O poai é universalmente comutativo, e porque uma relação de poai pode simplesmente ser imputada, por meio da atribuição de um nome, por qualquer motivo, ela também é universalmente aplicável. O poai devora o mundo e também devora a si mesmo. Pois quando uma criança permanece não nomeada por um período inaceitável de tempo após seu nascimento, ela adquirirá a designação poziawai, "não nomeada", geralmente devido ao medo de consequências indesejáveis. A criança então adquire uma relação de poai imediata com todas as coisas não nomeadas (não congruentes), mas, é claro, como poziawai é um nome, adquire uma outra relação com todas as coisas nomeadas (Wagner 2011a: 5). 
Wagner descreve acima um procedimento de analogia, com base no qual se estabelecem relações entre elementos a partir de suas semelhanças e diferenças. Em sua interpretação a respeito, o holismo novamente se faz presente: o nome daribi seria uma instanciação e uma simplificação da relação de poai, ser congruente com. E a relação de congruência é central para a fractalidade. Ela se dá em muitas instâncias: nomes, pele, parentesco $\mathrm{o}^{10}$ (cf. Wagner 1972, cap. 4). Qualquer coisa que receba um nome estaria, necessariamente, implicada nessa relação, ou seja, tudo estaria interligado. Até objetos ou pessoas que partilhem, cada qual separadamente, um ponto de semelhança com um terceiro objeto, estariam por meio deste interligados. A relação de poai poderia ser aplicada universalmente. Ela ocorreria por meio da linguagem, mas a partir de características intrínsecas às coisas ou pessoas. O que haveria nelas de intrínseco é que elas estariam predispostas a ser interligadas a outras a qualquer momento por meio da relação de poai. "O poai devora o mundo e também a si mesmo" (Wagner 2011a: 5), assim como o fractal. Até mesmo o nome "não nomeado" colocaria a criança em relação não só com todos os outros nomes que significam "não nomeado" como, sendo um nome, relacioná-la-ia a todos os outros nomes existentes. Mesmo a tentativa de não nomeação estabeleceria, pois, uma relação universal inescapável.

Cabe perguntar, entretanto, se uma outra forma de leitura da relação de poai não seria possível: ela não poderia apontar, antes, para a impossibilidade de equivalência total entre quaisquer elementos e, portanto, para a tênue analogia que os une, a qual contém, ao mesmo tempo, uma diferença inescapável que a própria relação de nomeação procura contornar? O estabelecimento da relação de poai parece apontar para dois abismos: o da diferença entre os elementos, sendo a analogia necessária para estabelecer entre eles uma relação, e o da diferença entre os elementos e seus nomes, que a atribuição de um mesmo nome a coisas distintas torna aparente. Se qualquer nome oblitera o próprio"11 (Derrida 1985), o próprio permanece um horizonte. E disso o nome "próprio" poziwai, não nomeado, é o melhor exemplo.

Wagner afirma que esses exemplos "servem para dirigir nossa atenção ao reconhecimento social do nome, único ponto de apoio a que os Daribi podem recorrer em uma superfície de outro modo isenta de atrito" (Wagner 2011a: 5). A ideia de que o social é isento de atrito a não ser pelas diferenças que nele insere a nomeação parece sustentar sua teoria. Assim, para Wagner, o nome é o que permite fixar uma relação específica em meio à infinidade potencial das relações. É a designação, para ele, que estabelece a relação aqui. Entretanto, parece escapar à teoria wagneriana da nomeação que qualquer nome, enquanto poai, indica mais e menos do que a pessoa nomeada na medida em que precede e excede essa pessoa (Butler 1997). Isso a despeito de sua etnografia apontar para o fato de que o nome é "tanto menos (...) quanto mais (...) do que a pessoa designada":

Como uma instanciação de poai, [a nomeação] sempre implica, por meio dessa relação, algo que é tanto menos (uma das muitas relações potenciais) quanto mais (uma classe, uma gama de objetos ou seres) do que a pessoa designada. Um homem que recebeu o nome do casuar, por exemplo, pode reivindicar palavras como tori, kebi e ebi como seus nomes, pois todas elas também são nomes do casuar. Além disso, como o casuar é poética e coloquialmente o ebi-haza, o "animal-casuar", em virtude de suas propensões não aviárias, esse homem bem poderia reivindicar haza, "animal", como pagerubo nobi, alcunha depreciativa (algo cômica) ou apelido. E se, como 
geralmente ocorre, o homem recebeu seu nome de outra pessoa, ou alguma outra pessoa recebeu seu nome, o nome, como a pessoa ou corpo conceitual, é sempre um seccionamento tomado de uma cadeia genealógica e implica essa cadeia (Wagner 2011a: 5).

A pessoa, assim como o nome, é simultaneamente mais e menos do que ela mesma porque o próprio do nome é uma quimera e a interpelação que o nome realiza coloca a pessoa na posição de sujeito, partilhada com todas as outras pessoas. A nomeação inevitavelmente traz consigo uma arquiviolência: a violência da obliteração do próprio (Derrida 1973[1967]). Como afirmar que o nome é um ponto de fixação em uma superfície de outro modo isenta de atrito se o próprio ato de nomear institui a diferença não só entre os nomes, por um lado, e o nome e a coisa, por outro, mas também entre a coisa e ela mesma?

Uma breve digressão por outro texto de Wagner, Asiwinarong, fornece-nos um exemplo empírico da obliteração do próprio: os leges, casais culpados de quebra da exogamia das metades, e sua descendência entre os Barok:

Todos os Barok cujo nascimento é normal pertencem, por nascimento, à metade de suas mães, e todas as metades são estritamente exógamas. A quebra da exogamia entre as metades é denominada leges. As pessoas culpadas de casarem-se no interior de suas próprias metades são sujeitas a desaprovação e humilhação social: seus nomes, bem como todos os termos de parentesco, não são usados, e as pessoas se dirigem e referem a elas simplesmente como leges. Os usos por meio dos quais o ideal de tolerância, ou malum, é eliciado entre as metades também são abandonados, e cada membro de uma união leges deve "comprar a vergonha" de seu ato com dez pram de mis ou um porco. Diz-se que nos tempos tradicionais os leges eram punidos com estrangulamento público. Os filhos de um casamento leges seriam automaticamente atribuídos à metade oposta e chamados apenas pelo nome, sem recurso à terminologia de parentesco. [...]

Ao desclassificar os transgressores das relações de parentesco e do malum, o leges equivale a um tipo de inversão punitiva da evitação que exerce normativamente um papel constitutivo no casamento usen. Em vez de eliciar uma relação pela atenção cuidadosa a certas proibições, os leges são relegados a um ostracismo no qual os próprios termos e ações que ordinariamente serviriam para eliciar a relação devem ser evitados. Para os leges, a evitação torna-se um fim, e não um meio com vistas a um fim. [...] Estabelece-se uma distinção entre os filhos de um casamento leges e os filhos ilegítimos, naron ni ngas ("irmãos da estrada"), que são tratados com uma desaprovação mais velada (Wagner 1986b: 55).

A redução de status social de que os leges são vítima é marcada pelo nome a eles atribuído. A obliteração do próprio é aqui extremamente violenta: a pessoa cujo lugar social é obliterado pela quebra da convenção recebe, como nome "próprio", o nome do tabu que transgrediu (/eges). Essa nomeação, além de apontar para a violência da segregação, que substitui a violência original (pré-contato) do estrangulamento na narrativa wagneriana, marca sua entrada no que seria o contrário da reciprocidade, tradicionalmente eliciada pela relação de malum entre as metades. Segundo Wagner, o sistema de metades barok permitiria a eliciação comportamental de um ethos no qual duas metades opostas seriam produzidas enquanto tais a partir da reivindicação de propriedade absoluta sobre seus membros matrilineares, que dela fariam parte, e do cuidado (nurturance) da outra metade. A pertença às metades - e a consequente diferenciação entre elas - seria eliciada por meio dos comportamentos de malum (contenção por respeito) e malili (oferta por alegria) (Wagner 1986b cap. 3). Ao optar por uma descrição do sistema de metades que não se pauta 
pela descendência, mas pela eliciação de diferenças, o autor mostra como o parentesco é, entre os Barok, produto de eliciação constante. A eliciação permitiria, pois, em alguns casos, a reconfiguração das relações de parentesco entre as pessoas para permitir o casamento delas a partir de uma mudança ritual nos padrões de interação entre os envolvidos. Cabe perguntar, portanto, por que o mecanismo da eliciação não poderia ser utilizado para dar conta da transgressão do princípio de exogamia entre as metades (leges).

O caso dos filhos de leges parece apontar para o resíduo do significante flutuante, para a impossibilidade de equivalência entre a norma e a prática, entre o significante e o significado: a quebra da lei que a etnografia wagneriana dos Barok nos apresenta como absoluta. A obliteração do próprio é aqui paradoxal: os leges são designados apenas pelo nome próprio, ao passo que a relação clânica, que lhes seria não só própria como apropriada, é suprimida de sua nomeação. Eles não só não recebem o nome de sua linhagem, o qual os colocaria em relação de continuidade com ela, como são designados membros da metade oposta, com a qual em princípio não manteriam laços de parentesco. Todos os que rompem com a exogamia recebem um mesmo nome, leges, atrelado a um lugar social. Esse tipo de nome parece procurar romper com a analogia da relação de poai ao designar um nome e lugar social apartado para os leges, numa tentativa de desvincular seu nome do nome de todos os outros. Mas se todos os leges se assemelham por serem excluídos da relação de reciprocidade entre as metades, seus filhos seriam a diferença no interior da diferença, na medida em que são incorporados à metade à qual não pertencem, mas não estão ligados a ela pelo nome clânico. E essa diferença no interior da diferença, nesse caso exacerbada, estaria presente em todas as formas de nomeação, em maior ou menor grau. Afinal, entre um significante e um significado nunca há equivalência absoluta; há sempre algum grau de flutuação.

Se o nome, em sua obliteração do próprio, excede e precede a pessoa nomeada na medida em que a localiza no mundo, cabe questionar a própria distinção estabelecida por Wagner entre as ideias de nomeação [entitlement] e nominação [nomination]. Afinal, não se pode falar em uma distinção absoluta entre o nome e a posição que ele designa. $O$ ato de nomeação seria, assim, o primeiro ato de instituição de um lugar social, e portanto de instituição da diferença. FP insiste, contudo, na ausência de atrito da fractalidade:

\begin{abstract}
Portanto, os pontos de convergência particulares que outros regimes melanésios de nominação podem ou não partilhar com a nominação daribi são, de certa forma, irrelevantes. Na medida em que as palavras são polissêmicas (e, é claro, a nominação as faz assim) e as pessoas se relacionam por meio de reprodução, qualquer sistema de identidades desenvolvido pelo seccionamento e referenciamento de um campo relacional desse tipo é intrinsecamente fractal (diferenciação aparente desenvolvida com base na congruência e intercambialidade universais). E como a denominação é nosso mapa ou modelo mais certeiro para a apreensão da identidade, o argumento em prol da conceitualização nativa de unidades fractais é evidente. $\mathrm{O}$ "indivíduo" e o "grupo" é que são arbitrários, impostos e artificiais (Wagner 2011a: 6).
\end{abstract}

Parece que as diferenças entre "os melanésios" se tornariam irrelevantes em virtude da semelhança que os caracterizaria em oposição aos "ocidentais". Ou, mais do que isso, a forma de nomeação "melanésia" permitiria perceber que mesmo entre os "ocidentais" a reprodução e a nomeação seriam fractais. A ideia 
defendida é de que qualquer sistema de seccionamento e referenciamento em um campo relacional é intrinsecamente fractal porque as pessoas se relacionam por meio de reprodução e as palavras são polissêmicas. A polissemia da linguagem leva, aqui, à unidade fractal. Entretanto, a polissemia não necessariamente conduz à fractalidade. Abandonando-se o pressuposto da ausência de atrito e da autorreplicação, a polissemia poderia ser apreendida não mais como replicação do mesmo que mantém sua escala, mas como disseminação - como o processo de diferenciação infinita que se dá na iteração dos nomes - iteração esta que coloca a possibilidade simultânea de permanência e mudança na relação entre significante e significado. Ora, se a ausência de distinção entre parte e todo guarda semelhanças com a différance derrideana, a holografia/fractalidade distancia-se consideravelmente da formação de traços pela iteração, pois a reprodução de si com retenção de escala defendida por Wagner é necessariamente replicação do mesmo. Se abandonarmos o pressuposto de que o nome se cola à coisa, percebe-se que a nomeação é tanto uma tentativa de essencialização (de dizer o que é de forma fixa) quanto a inevitabilidade da différance: movimento infindável de diferenciação sem referência a uma origem, adiamento, desvios de um significante estranho a si mesmo (Derrida 1972: 71), a impossibilidade do estabelecimento de bordas definidas. Porque em toda equivalência há um resíduo de significação que flutua e desloca.

\section{ENTRE A GENERALIZAÇÃO E A DIFERENCIAÇÃO, A MOEDA}

Não coincidentemente, Wagner volta-se para o conceito de moeda ao se contrapor à teoria da representação ${ }^{12}$ :

O conceito de moeda, dinheiro que exige contabilidade em termos de singularidade e pluralidade, é também uma imposição não fractal sobre um regime de trocas baseado em seccionamentos tomados da produtividade e da reprodutividade humanas. Porcos, conchas de madrepérola, machados e mantos de cascas de árvore já são relacionais e estão implicados na congruência que subjaz à recriação da forma, do sentimento e da relação humanos. As conchas e a riqueza em forma de conchas (as quais são pensadas pelos Daribi como sendo "ovos" por meio dos quais os seres humanos se reproduzem) estão implicadas na reciprocidade de subjetivos envolvidos na exibição e no ocultamento, assim como os machados, a carne e outros acessórios da produção e da reprodução colocam o sustento e a replicação humanos em relação de troca recíproca. Quando esses pontos relacionais são tratados como sendo da ordem da representação, como agregados de mercadorias com base no modelo da moeda, ou quando a moeda que os substitui é tomada literalmente, a relação integral é negada e distorcida. Uma vez suprimida a congruência que mantém a escala de sua unidade essencial por meio de todas as permutações de categorização, os nomes convertem-se em meras categorias representacionais de designação social e classificação. E excluído o sentido de sua unidade essencial com o corpo e o processo vital (...), os itens trocados tornam-se meros "objetos de riqueza" de uma categorização semelhante - uma "representação" dos valores humanos por meio da utilidade, uma "classificação" das utilidades por meio do valor humano (Wagner 2011a: 6).

O dinheiro seria, pois, uma imposição sobre a forma de pensamento "melanésia" não porque é abstrato, mas porque lida com singularidade e pluralidade quando os melanésios funcionariam por meio da fractalidade; porque seria da ordem da representação enquanto a troca melanésia seria reciprocidade e 
congruência. Mas por que o dinheiro não poderia, aqui, ser relido pelos melanésios na chave da fractalidade, como acontece em outros autores que trabalham a partir da ideia de uma assimilação pela perspectiva nativa dos elementos introduzidos pelo "contato", como em Sahlins (2003)? A razão para isso parece ser a abordagem mais nostálgica do que histórica. Afinal, se a introdução da moeda costuma estar vinculada a inúmeras mudanças sociais, políticas e subjetivas, compreender o processo dessas mudanças requer uma análise histórica. Contudo, a ideia defendida é de que os seccionamentos relacionam-se à produtividade e reprodutividade humanas no regime de trocas daribi, algo que o dinheiro não faria. Mas o dinheiro não relaciona tudo ao possibilitar que todas as coisas tenham um valor de troca abstraído do valor de uso? O problema parece ser, antes, que o dinheiro não estava posto para os melanésios antes do contato e sua abstração promove o seccionamento do vínculo essencial entre o nome e a coisa - é da ordem da representação. Há em Wagner um afeto que deseja manter os Daribi longe desse contágio, pois em sua propensão para a relação poderiam acabar por relacionar-se a tudo, inclusive ao que seria deles em princípio distinto, como o mundo ocidental.

Em Asiwinarong, sua visão sobre a convivência entre a moeda "tradicional" (mangin) e o dinheiro não é tão crítica, pois nenhuma das acepções de mangin parece ter precedência sobre as outras na descrição de Wagner, que chega a estabelecer uma relação com o "sistema mundial" de Wallerstein:

Em seu uso, o mangin barok aproxima-se das funções de três tipos de moeda: a "riqueza vital" (...) que circula nas terras altas da Nova Guiné; (...) o "dinheiro", na acepção ocidental, parte de uma economia de bens ou "coisas" produzidas, e o "dinheiro" como meio para o mérito ou a supremacia moral. Ele é o principal marcador da troca no casamento e em outros ritos que contêm o ciclo da criação [nurturance] humana; ele pode ser trocado por moeda papuana ou por bens, como porcos e terra, que também podem ser convertidos em dinheiro; e é o meio preferido para o pagamento de multas, a "compra da vergonha" e todas as transações no taun. Assim, em seu uso, o valor de mangin aproxima-se de uma espécie de tripla metáfora: cada padrão de troca afasta-se da certeza da definição dos outros dois. Como essa escala de valores inclui a "moeda humana" da riqueza da noiva, dos pagamentos por morte e de várias avaliações retributivas, haverá certa tendência a "converter" mangin em "riqueza da noiva" e a analisar os Barok em termos de linhagens corporadas. E como a credibilidade do valor universal ("propriedade, produção, consumo") é reforçada pela credibilidade "real" da troca no que Immanuel Wallerstein chama de "sistema mundial" - porque mangin de fato pode ser trocado por kina, e kina por dólares -, haverá teoricamente a possibilidade de realizar a troca de mangin dessa forma também (Wagner 1986b: 83-84).

Neste momento da obra de Wagner, em que ainda não há privilégio da holografia e da fractalidade, a introdução da moeda não é retratada como algo que faz ruir a estrutura social do great man. Pelo contrário, é como se o conceito "barok" de moeda já contivesse e desse conta de incluir todas essas possibilidades. Elas são negociadas e as relações entre as pessoas é que determinam seus efeitos. Já em FP, a questão parece ser como manter esse relativismo que se recusa a pensar a violência como intrínseca à outra sociedade sem postular que o "contato" não é nem bom, nem ruim. Pois para opor-se ao contato de modo convincente, é preciso levar em conta a violência constitutiva do que é aqui denominado "melanésio". Não só a violência é um componente indissociável da linguagem, como qualquer sistema de nomeação está eivado de violência, suprimida na narrativa wagneriana de FP. Os ecos da "Lição de escrita" (Derrida 1973) não são gratuitos: 
apontam para a incongruência que frequentemente se embrenha nos textos antropológicos que buscam no "outro" a solução para os problemas que veem em si. Será a alteridade pressuposta com esse fim?

Não é fortuito que o problema para Wagner seja a ideia de representação relacionada ao dinheiro. A representação distorce a relação integral porque coloca para ela uma abstração, a qual faz com que o nome se despregue da coisa nomeada. A mercadoria é um problema para Wagner porque distorce e nega a relação integral; interrompe a congruência entre os elementos no plano fractal, cuja pretensão é prescindir da representação, ser uma forma de instanciação imediata. É como se, antes do "contato" - nas origens - , o nome e a coisa fossem um: a ausência de distanciamento entre significante e significado, separação insustentável, quando tornada absoluta, entre linguagem e violência. É esta a defesa explícita de Wagner em TIC ao falar da linguagem no modo de invenção diferenciante (atribuído aos "povos tribais"). Sua nostalgia é de um suposto momento em que o nome e a coisa eram um: uma nostalgia das origens. Contudo, o processo de diferenciação pode ser pensado, como na différance, não só entre o nome e a coisa, mas também no interior do próprio nome, pois o significante é sempre excessivo em relação ao significado: Daribi em relação a melanésio, Daribi em relação a Daribi, melanésio em relação a melanésio. A partir dessa perspectiva, a diferença no interior do mesmo passa a ser tão infinita que não mais se pode falar em mesmo e outro, pois a diferença, assim como a semelhança, está em toda parte. Ora, se isso é assim, a diferença, encontrada tanto no interior do mesmo quanto do outro, prescinde do conceito de alteridade, que só faz sentido em contraposição à ideia de que existe um mesmo ao qual se opor ${ }^{13}$.

Em FP, o dinheiro é apresentado por Wagner como vanguarda do sistema mundial. Ele conta os recursos de forma abstrata, enquanto no caso dos Daribi os recursos seriam, eles mesmos, relacionais: fariam parte da relação e exerceriam "seu próprio efeito reflexivo sobre os termos da avaliação" (Wagner 2011a: 6). É por isso que "o preço da noiva e das crianças são imensamente inflacionados" (Wagner 2011a: 6). Mas como falar em inflação fora do contato? Não é este um conceito que só cabe em relação à concepção de dinheiro como abstração? Se a mercadoria é inseparável das relações, essa conclusão não se sustenta. A inflação seria uma forma de relacionar, mas onde? No sistema daribi apartado do contato, ou há aqui um reconhecimento implícito da impossibilidade de separação radical entre o pré e o pós-contato? 0 trecho a seguir parece confirmá-lo:

Será a imagem "econômica" do big man meramente efeito dessa retórica quando maximizada por meio da comensuração literalizante dos objetos e de sua avaliação? Assim, nossa própria imagem do big man inflaciona-o ao Ihe imputar sua própria inflação, ao passo que sua atribuição nativa distintiva é a de um retórico [...]. Pois no limite, o árbitro final do dinheiro, assim como da lei e dos casos judiciais, da etnografia e do status nativo, é a fala. $E$ a fala, um conceito que geralmente inclui a linguagem para os melanésios, não é de modo algum o mesmo que descrição, avaliação, informação ou a própria linguagem. Ela é o meio de sua fractalidade, aquilo que expande ou contrai a escala de reconhecimento e articulação para se adaptar a todas as exigências, fazendo com que a linguagem seja igual a todas as ocasiões ao transformar essas ocasiões em fala. A fala é, pois, como uma relação de poai intrínseca ao pensamento. Espera-se que a Lei e o Dinheiro, o singular e o plural, o indivíduo e o grupo, e mesmo a etnografia, sejam os lugares nos quais a fala vem repousar; mas a fala sobre a Lei e o Dinheiro, e mesmo a etnografia, nunca repousa; e a fala ela mesma [...] nunca morre. É esta a fractalidade da pessoa melanésia: a fala formada por meio da pessoa que é a pessoa formada por meio da fala (Wagner 2011a: 6). 
Portanto, para Wagner, nós inflacionaríamos o big man ao imputar-lhe sua própria inflação, mas o que o distinguiria para os melanésios seria o fato de ser um retórico, um mestre da fala. O big man seria um retórico da asserção, pois a fala, e não a representação, seria o árbitro final entre os melanésios. Ora, é na fala que o nome pode ser colado à coisa, e ao que parece o nome só pode manter com a coisa uma relação de imediaticidade na fala. Mas se os nomes e as coisas são um, como explicar a necessidade da retórica e o dissenso inerente à linguagem? Aqui se manifesta, uma vez mais, a recusa wagneriana da distância entre o significante e o significado. Segundo Wagner, a fala inclui a linguagem para os melanésios, e não o oposto. Contudo, para ele a fala não é o mesmo que a linguagem, mas o meio de sua fractalidade: ela faria com que a linguagem fosse igual a todas as ocasiões porque transformaria todas essas ocasiões em fala. A fala seria "como uma relação de poai intrínseca ao pensamento". Na Melanésia, a fractalidade da pessoa seria dialética: ela se formaria pela fala e, por sua vez, formaria a fala. A fala incluiria a linguagem. Não seria o mesmo que a linguagem porque a incluiria. Mas não seria a inclusão, aqui, um modo de manifestação do mesmo?

É interessante que o ponto de ruptura de tantos textos antropológicos seja justamente o momento em que pretendem estabelecer a fala como o lugar em que o nome e a coisa se equivalem. Encontramos aqui a iteração de um gesto nostálgico recorrente nas ciências humanas: o desejo de presença real no discurso. Espera-se que a fala venha repousar na Lei, pois a Lei deve ser imutável. Todos os opostos da dialética wagneriana repousam, pois, na fala, que sendo uma deve reproduzir todos os outros. Mas se a fala é um meio, ela é também um pharmakon (Derrida 1972); se é atividade constante - atividade que Wagner gostaria que replicasse o mesmo -, é iterativa e, como tal, pode ser transformada. A fala de Wagner, sem a ambiguidade do pharmakon (que é não só escrita, mas também logos, fala e argumento, razão falada), não se sustenta. Se a linguagem transforma todas as ocasiões em fala, passa a ser igual a todas elas. Assim, a fala passa a ser um evento, e como tal, iteração. Ora, é a iteração que coloca a possibilidade de mudança para além da replicação do mesmo.

\section{ETNOGRAFIA，VIOLÊNCIA，ORIGEM}

O incômodo de Wagner, contudo, parece ser com o fato de que os nomes, tomados por nós como dados, são seccionamentos arbitrários do "tecido da congruência universal":

Quando os seccionamentos arbitrários recortados na totalidade do tecido da congruência universal são tomados literalmente como dados, eles se tornam as categorias sociais que identificamos como nomes, indivíduos, grupos, objetos de riqueza e sentenças ou afirmações portadoras de informações. Assim tomados a partir de seu valor nominal, eles perdem qualquer senso de fractalidade e se fundem com a hegemonia ocidental de ordens sociais formadas por elementos substantivos, sistemas culturais feitos de categorias representacionais. Isto não significa que as possibilidades fractais de retenção de escala não estejam lá, pois elas são evidenciadas pela relação de poai e seus vários equivalentes. Mas implica de fato uma forte garantia de que a consciência e o uso nativos 
dessas possibilidades serão desconsiderados, negligenciados ou mal-interpretados como tentativas rústicas de construção social (Wagner 2011a: 7).

A crítica aqui, repetida em outros momentos, é de que ao tomar as coisas por seus nomes, a antropologia faria com que as categorias fossem tomadas por seu valor nominal; com isso, deixariam de ser fractais, de reter sua escala: já não refletiriam o pensamento nativo, pois operariam com base na representação. Caberia, contudo, colocar algumas questões: se partirmos dos nomes "daribi" não estaremos simplesmente substituindo um seccionamento arbitrário por outro? Os nomes com que se totaliza um "outro" também não são seccionamentos arbitrários? Se for este o caso, como podemos falar em "Daribi" ou "melanésio"? A fractalidade é defendida a partir de um seccionamento, "ocidental" versus "melanésio", e suas várias atualizações. Segundo essa forma de nomeação, os nomes "ocidentais" perderiam a fractalidade, ao passo que os nomes "daribi" seriam fractais por serem instanciações de um modo de ser fractal. Disso resulta a conclusão paradoxal de que não podem, pois, ser "daribi". Por que, então, a partir dessa perspectiva, insistir nas denominações "melanésio" ou "Daribi" para se referir à forma como as coisas "de fato" são? E como sustentar que a forma de simbolização "deles" deve nos colocar no caminho da compreensão das coisas se esses nomes são apenas um seccionamento "arbitrário, imposto e artificial"?

Parece haver aqui uma contradição. Ou "os Daribi" são apenas um nome, e isso em certa medida os destitui de sua singularidade, ou eles "de fato" são Daribi, o que contradiz a ideia de que as formas do humano são fractais e mantêm sua escala. A questão à qual chegamos, de maneira oblíqua, é a de como fundamentar a afirmação de que o modo de simbolização nativo é fractal. Há ainda uma questão que a antecede: como fundamentar a ideia de um pensamento nativo circunscrito por um nome? Se o pensamento nativo está no lugar da estrutura em Roy Wagner, cabe a ele a mesma objeção clássica ao estruturalismo: assim como não há nada que sirva de fundamento à estrutura, não se pode garantir a existência de um pensamento ímpar pertinente a um grupo social. O pensamento nativo parece ser, pois, tão arbitrário quanto o conceito de social. Mas essa arbitrariedade não é posta em questão, pois admiti-lo significaria reconhecer a ausência de fundamento de qualquer noção de "todo".

Ora, é da noção de todo que decorre a concepção wagneriana de poder:

A fractalidade, assim, relaciona-se ao todo, converte-se nele e o reproduz, e é algo tão diferente de uma soma quanto de uma parte individual. Uma forma holográfica ou que estabelece sua própria escala difere, portanto, de uma "organização social" ou de uma ideologia cultural na medida em que ela não é imposta de modo a ordenar e organizar, explicar ou interpretar, um conjunto de elementos díspares. Ela é uma instanciação dos próprios elementos (Wagner 2011a: 7).

Se a origem do poder é o todo, seu fundamento deixa de ser violento. A "forma holográfica" seria diferente da "organização social" ou da "ideologia cultural" porque a ordenação, a organização, a explicação, a interpretação que ela promove não seriam impostas. Ela seria uma instanciação dos próprios elementos, ou seja, inseparável deles. Essa ânsia de imediaticidade parece ser mais uma manifestação da metafísica da presença ${ }^{14}$, necessidade de presença a si, tentativa de expulsão da contradição que clama pela estabilização 
da relação entre significante e significado, pela equivalência entre o nome e a coisa. A organização social ou ideologia cultural, ao impor uma escala, afastaria os elementos de si mesmos, subsumindo-os a uma lógica que Ihes seria estranha, e nessa medida os apartaria de sua origem e da possibilidade de instanciarem-se a si mesmos, como seria possível com a fractalidade caso ela pudesse ser atribuída a um nome (melanésio, daribi, barok, etc.) e ainda assim operar fora da linguagem. Como isso é impossível, procura-se fazer com que a linguagem reflita o mundo, e essa linguagem é buscada alhures, num lugar povoado de outros.

O trecho a seguir, no qual Wagner se contrapõe explicitamente aos "estratagemas desconstrutivos", é especialmente interessante para pensar seu distanciamento em relação à disseminação:

A fenomenalidade do significado fornece um paralelo adequado - não existe algo como uma "parte" de um significado. Ainda que possamos nos convencer, por meio de gramáticas, sistemas de signos, estratagemas desconstrutivos e similares, de que os meios pelos quais nós eliciamos significado podem ser eminentemente partíveis, os significados assim eliciados não têm e não podem ter partes. Não se trata simplesmente do clichê de que os todos são maiores do que as somas de suas partes, pois se um significado não tem partes, não há soma que se possa comparar com a totalidade. Também se poderia concluir que o todo é menos do que a soma, já que ele é apenas um. Quando um todo é subdividido dessa forma ele é segmentado em hologramas dele mesmo; ainda que nem a segmentação, nem tampouco seu oposto, equivalham a uma função "ordenadora". O que denominamos uma "ordem" pertence ao mundo da partibilidade e da construção (Wagner 2011a: 7).

Assim, para Wagner, os significados que vêm à tona por intermédio da eliciação não podem ter partes. O curioso, entretanto, é que sua argumentação, neste ponto, torna-se emotiva: o texto é movido pelo afeto holístico. Onde o logos falha, a escrita, em seus traços, revela o afeto. Por que não pode o significado ser partido? O que garante que, a despeito da polissemia, um determinado aspecto do significado não possa ser privilegiado em relação a outros, inúmeros, apontados pelo significante? A crítica de Wagner a Alfred Gell vai também nesse sentido, na medida em que o problema, para ele, parece ser o fato de Gell dissociar "as imagens condensadas em oposições e categorias lineares" (Wagner 1992: 206). Como alternativa à partição do significado, Wagner apresenta a proposta de manter a escala por meio da imagem. Uma vez mais, o que serve de caução a sua defesa da não divisão da imagem em partes menores é a "experiência nativa do ritual como poder concreto, imagético" (Wagner 1992: 207).

O fundamento inamovível da argumentação wagneriana parece ser o de que o todo é um. Isso posto, o todo, quando dividido, é segmentado em hologramas dele mesmo. A totalidade precede a contagem. Entretanto, para aceitar esse suposto seria necessário abrir mão dos polos da dialética, do "eu" e do "outro", ou então subsumi-los como instanciações desse grande um: em última instância, seria preciso abrir mão da diferença. Uma escolha difícil para a antropologia. Resta saber como a "Lei" e o "Cosmos", se ordenam o pensamento, vieram a permitir esse filho bastardo que é a différance, a qual, entretanto, oferece uma resposta provocadora: toda possibilidade de transgressão está contida na própria lei, que não só a proíbe, como clama por ela (Derrida 1994). Ora, a cada iteração, a possibilidade de reproduzir ou subverter a lei se coloca. Ao que tudo indica, a reiteração da holografia/fractalidade na instanciação é um esforço de iteração 
da ordem do cosmos na modalidade da reprodução integral, esforço de reprodução que não pode deixar de correr o risco de transformar-se a cada nova iteração. Contudo, Wagner insiste na permanência:

Mas se a holografia importa para esta discussão, não é como fenômeno etnográfico, mas antes como modo de entendimento. (...) Nada é construído e nada é dissecado nesses exemplos; eles não são nem construção, nem desconstrução, mas simplesmente uma replicação adicional da fractalidade no entendimento do etnógrafo. Poderse-ia dizer que a holografia nativa é um reinterpretar das ideias do antropólogo e, no processo, um reinterpretar da própria interpretação (Wagner 2011a: 10).

Se os exemplos não constróem, não desconstróem e não dissecam, Wagner deseja apresentar uma alternativa a essa oposição: apropriar-se do entendimento nativo - a fractalidade - e replicá-lo novamente, segundo a lógica dos fractais. Ou melhor, é a holografia nativa que se replicaria nele, pois ela reinterpretaria o antropólogo; reinterpretaria sua interpretação. É esta a antropologia reversa defendida em TIC. A desconstrução, e também a construção, seriam obstáculos a isso. A holografia nativa reinterpretaria a interpretação do antropólogo, o qual reproduziria, replicaria a holografia. Pois o entendimento do etnógrafo se daria a partir da contraposição e do diálogo entre suas próprias conceitualizações e a holografia nativa. O antropólogo seria, portanto, um meio: um pharmakon, ao mesmo tempo remédio e veneno. Assim, sua descrição não poderia afastar a violência inerente a qualquer processo de tradução.

Wagner defende a "totalização holográfica do mundo conceitual" e coloca a necessidade de reconhecermos a fractalidade pessoal (superação da dicotomia entre indivíduo e sociedade), resultado de uma interpretação que não é "uma união forçada de elementos díspares", pois nela não há mudança de escala. Sua defesa é, portanto, de uma antropologia que não opere a partir da lógica da mudança de escala, nem tampouco da introdução de elementos não postos pelo objeto em sua explicação ("construcionismo"). Diferentemente da desconstrução ${ }^{15}$, o autor pretende acessar um melhor entendimento do mundo por meio de conceitualizações "nativas", as quais se encontrariam disponíveis para ele. Nos termos de Wagner, a relação entre o antropólogo e o nativo, polos opostos, deve ser de complementaridade dialética, e não de substituição. Os polos dessa dialética devem manter uma relação que contribua para que sejam cada vez mais eles mesmos e, portanto, distintos. Para que a dialética wagneriana opere, a oposição não pode ser dissolvida em disseminação ou suplemento. Contudo, cabe perguntar se a desconstrução coloca de fato a necessidade de uma análise a partir de fora ou, antes, a necessidade de desestabilização dessas fronteiras.

Entretanto, essa disponibilização da perspectiva do outro, que lhe permite argumentar contra as teorias de sua "própria" sociedade e cultura, somente é possível porque o antropólogo detém o poder de nomeação da alteridade. Está em suas mãos a possibilidade de, ao nomear o outro, situá-lo no polo oposto da dialética do entendimento. A superação da "própria" perspectiva depende da nomeação do outro, do gesto êmico. Ora, a desconstrução, da qual Wagner se distancia no desejo de replicar o que apresenta como aquilo que "de fato" é, reconhece que não se podem ultrapassar as oposições, mas somente desestabilizá-las ao mostrar como o fundamento sobre o qual foram erigidas é frágil e se sustenta apenas pela violência que institui a origem. Wagner pretende saltar por sobre as oposições conceituais recorrendo à conceitualização 
melanésia. Mas para tanto, vale-se da clássica oposição entre nós e eles, ocidental e melanésio, a qual propõe superar afirmando que a fractalidade não é generalização, mas o próprio meio de análise de si mesma:

[As] evidências aqui apresentadas indicam que ao menos para alguns povos melanésios as formas de conceitualização social e cultural mantêm sua escala através de todas as permutações rituais e pragmáticas. Isso porque em uma conceitualização desse tipo, fractal ou que mantém sua escala, o próprio conceito se funde com o espaço de sua concepção, e refazer o mapa dos dados com base em escalas artificiais e externas não resulta em nenhum ganho. Se a maior parte dos problemas sociais e culturais depende da hegemonia ocidental para que sejam meramente imaginados, isso sugere que as exigências de viver e pensar em muitas culturas melanésias são bastante diferentes da forma como os cientistas sociais as entenderam (Wagner 2011a: 10-11).

A alternativa à análise seria, portanto, a tautologia, ou seja, o momento em que se abre mão da justificativa: "a fala que se volta para si mesma" (Wagner 2008: 77). A alternativa seria seguir os modos de entendimento "nativos"; e a analogia, aqui, seria o modo de operação desse seccionamento. A analogia seria a forma de operação da fractalidade, o que permitiria ao autor afirmar que "o todo nutre a si mesmo" por meio desses seccionamentos transversais. A dialética wagneriana, em sua tautologia, pretende prescindir de síntese: na circularidade desse pensamento, os limites se estabelecem em troca da segurança oferecida pela replicação do uno. A holografia, ao totalizar o mundo conceitualmente, transforma o problema da oposição e da violência em uma reiteração da complementaridade ${ }^{16}$.

A conclusão a que se chega a partir de suas premissas é emblemática:

Assim, a tarefa do great man não seria, portanto, aumentar a escala dos indivíduos para gerar agrupamentos, mas manter uma escala que é pessoa e agregado ao mesmo tempo, solidificando uma totalidade em acontecimento. A forma social não é emergente, mas imanente. Se isso lembra a poderosa evocação do holismo no sistema de castas hindu por Louis Dumont, com sua fractalidade da unidade brâmane, também ressoa o conceito de "divíduo" de Marriott: a pessoa, como a sociedade, que é todo e parte ao mesmo tempo.

Em última instância, trata-se de pedaços que são recortados do tecido da experiência diferentemente do que nós poderíamos esperar. A fractalidade lida com totalidades, não importa quão finos sejam os cortes, e é por esta razão que eu insisti nos temas da mudança de escala e da maximização. Pois a questão dos great men e big men é, em última análise, uma questão de maximização. O big man como produto da inflação etnográfica é o resultado da maximização estatística e sociológica, um aparente congregador e dispersor de pessoas. Mas a concepção fractal de um great man começa com a premissa de que a pessoa é uma totalidade, e qualquer acréscimo a ela não é mais do que uma realização parcial. A totalidade é, em outras palavras, conceitual, e não estatística. O great man, sem especificidade de gênero, torna-se grande por uma instanciação ou configuração particular de uma totalidade conceitual (Wagner 2011a: 11).

O êmico garante, pois, a reiteração do fractal. E a fractalidade wagneriana não abre espaço para a diferença no interior do nome. Os ritos e as atividades pragmáticas seriam "permutações" desse fractal, e é nessa condição que manteriam sua escala. A ideia que está por trás da teoria da fractalidade/holografia parece contradizer, pois, a invenção como agência, como parece ser o caso em TIC. Como pensar a invenção em relação dialética com a convenção, e assim moldando o fluxo dos acontecimentos, se todo e qualquer evento for uma replicação fractal do grande "tecido da congruência universal"? Em outras palavras, onde 
estão a diferença e a diferenciação? Paradoxalmente, a antropologia da fractalidade/holografia acaba, ao defender de forma radical que se olhe para a conceitualização da alteridade, por instaurar a prevalência da alteridade em detrimento da compreensão dos processos de diferença ${ }^{17}$. Isso coloca a seguinte questão: como conciliar a tentativa de questionar as bases epistemológicas da antropologia a partir do diálogo com a diferença (em TIC, necessariamente dialético) e a defesa da fractalidade como forma de entendimento universal, que no entanto depende do nome de uma particularidade? A ideia de que o social é imanente, e por isso não precisa ser explicado, aponta para as instanciações da fractalidade como ausência de processo no sentido forte do termo. A tentativa de fundamentar a fractalidade nos nomes dos outros, entretanto, mostra como ela é antes uma tentativa de congelar a equivalência entre o nome e a coisa do que uma solução para o processo (inevitável) de différance que constitui a nomeação. A defesa wagneriana da fractalidade depende, paradoxalmente, de um gesto que circunscreve a diferença do outro via nomeação.

Iracema Dulley é Doutora em Ciências Sociais (Antropologia Social) pela Universidade de São Paulo (USP) e realiza pós-doutorado na London School of Economics (LSE). É pesquisadora do Centro Brasileiro de Análise e Planejamento (Cebrap). 
1 A esse respeito, ver também "O conceito de sociedade está teoricamente obsoleto", de Marilyn Strathern (2014).

2 Agradeço a Aramis Silva, Leopoldo Waizbort, Marcelo Mello, Marco Antonio Gonçalves, Paula Montero, Renato Sztutman e Suely Kofes pelos preciosos comentários a versões anteriores deste texto, bem como aos três pareceristas anônimos da Campos por seus estimulantes apontamentos, aos quais procurei responder. A pesquisa que deu origem a este texto foi generosamente financiada pela Fapesp, pelo que Ihe sou grata.

3 Wagner raramente nomeia os autores aos quais pretende se contrapor, com exceção do estrutural-funcionalismo (cf. Wagner 2010a) e estruturalismo. Sua concepção de great man vem, contudo, propor uma substituição de uma abordagem de caráter mais utilitarista por uma compreensão daquilo que o autor designa, em A invenção da cultura, como a "motivação humana em nível radical" (Wagner 2010b: 13), ou seja, as determinações de caráter cultural às quais qualquer utilitarismo estaria, para ele, necessariamente submetido. Sobre o diálogo de Wagner com a antropologia simbólica, ver Gonçalves (2010).

4 Para uma leitura da fractalidade wagneriana como "ontologia fractal", ver Shaffner (2010).

5 Wagner chega a afirmar que sua proposta seria praticamente a de um "estruturalismo sem estrutura" (Wagner 1986a). Para uma consideração das críticas de Wagner ao estrutural-funcionalismo e ao estruturalismo no que diz respeito a sua concepção dos grupos, ver Wagner (2010a) e Dulley (2015, cap. 4).

6 Ultrapassa o escopo deste artigo validar a afirmação de que a obra wagneriana pode ser lida como composta por diferentes momentos teórico-etnográficos até certo ponto descontínuos. A esse respeito, ver Dulley (2015).

7 TIC categoriza os modos de simbolização humanos como diferenciantes ou generalizantes, a depender de qual polo da dialética é mascarado na simbolização - o primeiro seria, grosso modo, o das "populações tribais"; o segundo, o "ocidental". Se o modo generalizante (convencional) opera, segundo o autor, estabelecendo uma distinção entre o símbolo e a coisa simbolizada, o modo diferenciante assimila ou engloba aquilo que simboliza. Entretanto, ambos os procedimentos - a diferenciação e a generalização seriam necessários para qualquer tipo de invenção: o que distinguiria as culturas seria a ênfase atribuída conscientemente a cada um desses modos na simbolização, com o mascaramento do procedimento oposto (controle). Ademais, o processo de simbolização se daria, em ambos os modos de simbolização, como dialética entre invenção e convenção.

8 Talvez se possa resumir o conceito de dialética wagneriano como um movimento pendular entre polos opostos como forma de negociar um paradoxo. Para mais detalhes, ver Dulley (2015, cap. 3).

9 Instantiation, no original, remete a instance, "exemplo". Os exemplos, em Wagner, devem ser entendidos como manifestações dessa mesma fractalidade.

10 Para instanciações amazônicas da fractalidade, ver Kelly (2001) e Zea (2010).

11 Em Derrida, a obliteração do próprio relaciona-se à impossibilidade de retenção de uma distinção definitiva entre nomes próprios e nomes comuns. Disso resulta a não singularidade dos nomes ditos próprios, que se aproximariam, em sua estrutura, dos nomes comuns - e portanto teriam sua propriedade obliterada (e.g. Derrida 1985).

12 A esse respeito, ver também Wagner (1977a: 629; 1986b, cap. 4).

13 Com isso não pretendo, contudo, propor uma forma única de pensar a diferença, especialmente em oposição aos mundos etnograficamente descritos - ou seja, substituir "melanésio" por "derrideano", por exemplo. Meu objetivo, ao trazer Derrida para o diálogo com Wagner, é o esgarçamento de algo que percebo como uma clausura da fractalidade - a qual não está posta da mesma maneira, por exemplo, em TIC, onde a dialética entre convenção e invenção prescinde do nome como fundamento. O que pretendo com Derrida não é substituir um particular por um universal ou vice-versa, mas desconstruir as fronteiras que permitem que se fale em universal e particular - as fronteiras do nome.

14 A ideia de uma metafísica da presença aponta para a suposição, insustentável mas recorrente, de que na origem nome e coisa seriam um. Derrida localiza a tendência de buscar na origem o significado primordial das coisas na tradição filosófica que se inicia 
com Platão e relaciona-a ao deslizamento de significados operado na tradução do pharmakon como veneno, a qual teria relegado, na tradição filosófica ocidental, a escrita à condição de subordinação em relação à fala em virtude de sua não imediaticidade, de sua separação em relação à origem da enunciação (ver Derrida 1972, 1973, 1995)

15 Para uma análise do engajamento wagneriano com a différance, por ele nomeada "dif/ference" em Wagner (1991), ver Dulley (2015: 227-237).

16 Não discutirei aqui a concepção de complementaridade entre os gêneros (entendidos como masculino e feminino) que perpassa a obra de Wagner (e.g. 2002). Entretanto, gostaria de assinalar, ainda que en passant, que sua visão holista dos gêneros como complementares desconsidera qualquer possibilidade de violência.

17 Maluf parece chegar, por outras vias, a uma conclusão semelhante: a de que a oposição entre "nós" e "eles" se baseia em uma "metafísica da substância", ou, nos termos de Butler, uma "ontologização da diferença", a qual, como apontado por Maluf, poderia ser vista como a convenção, no sentido wagneriano, não só da etnologia, mas de um "modo ocidental de inteligibilidade do sujeito" (Maluf 2010: 52). 
BUTLER, Judith. 1997. Excitable Speech. A Politics of the Performative. Nova York e Londres: Routledge.

DERRIDA, Jacques. 1972. La dissemination. Paris: Éditions du Seuil. 1973 [1967] Gramatologia. São Paulo: Perspectiva.

1985. “Des tours de Babel”. In: J. Graham (ed.). Difference in Translation. Ithaca: Cornell University Press. 1994. Force de loi. Paris: Galilée.

1995 [1967]. A escritura e a diferença. São Paulo: Perspectiva.

DULLEY, Iracema. 2015. Os nomes dos outros: etnografia e diferença em Roy Wagner. São Paulo: Humanitas. GONÇALVES, Marco Antonio. 2010. Traduzir o outro: etnografia e semelhança. Rio de Janeiro: 7 Letras.

HARAWAY, Donna. 1985. "A Manifesto for Cyborgs: Science, Technology and Socialist Feminism in the 1980s". Socialist Review 80: 65-107.

KELLY, José Antonio. 2001. "Fractalidade e troca de perspectivas". Mana 7(2): 95-132.

MALUF, Sônia. 2010. “A antropologia reversa e 'nós': alteridade e diferença". Ilha. Revista de Antropologia $12(1 / 2): 41-58$.

SAHLINS, Marshall. 2003 [1985]. Ilhas de história. Rio de Janeiro: Zahar.

SHAFFNER, Justin. 2010. "Nem plural, nem singular: ontologia, descrição e a Nova Etnografia Melanésia". I/ha. Revista de Antropologia 12(1/2): 103-136.

STRATHERN, Marilyn. 1990. Partial Connections. ASAO Special Publication no. 3. Lanham: University Press of America.

2014. O efeito etnográfico e outros ensaios. São Paulo: Cosac Naify.

WAGNER, Roy. 1972. Habu. The Innovation of Meaning in Daribi Religion. Chicago: Chicago University Press. . 1977a. "Analogic Kinship: A Daribi Example". American Ethnologist 4(4): 623-42.

1977b. "Scientific and Indigenous Papuan Conceptualizations of the Innate: a Semiotic Critique of the Ecological Perspective". In: T. Bayliss-Smith; R. Feachem (orgs.). Subsistence and Survival: Rural Ecology in the Pacific. Londres: Academic Press.

1986a. Symbols that Stand for Themselves. Chicago: University of Chicago Press.

1986b. Asiwinarong. Ethos, Image and Social Power among the Usen Barok of New Ireland. Princeton:

Princeton University Press.

1991. "Dif/ference and Its Disguises". In: R. Scharlemann. (org.). On the Other: Dialogue and/or Dialectics. Nova York: University Press of America.

1992. "The Imagery Keeps Its Scale: An Obviation Model of the Yafar Yangis". In: B. Juillerat (org.).

Shooting the Sun: Ritual and Meaning in the West Sepik (New Guinea). Washington: Smithsonian Institution Press.

2001a. An Anthropology of the Subject. Holographic Worldview in New Guinea and Its Meaning and Significance for the World of Anthropology. Berkeley: Los Angeles: Londres: University of California Press. 
2002. "Edith Turner: The Gender of Giftedness". Anthropology and Humanism 26(2): 190-194.

2008. "Lost Horizons at Karimui". In: T. Kaartinen; C. Sather (orgs.). Beyond the Horizon: Essays on Myth, History, Travel, and Society. Helsinki: Finnish Literature Society.

2010a. "Existem grupos sociais nas terras altas da Nova Guiné?". Cadernos de Campo 19: 237-257.

2010b. A invenção da cultura. São Paulo: Cosac \& Naify.

2011a [1991]. "A pessoa fractal". Ponto Urbe 5: 1-12.

2011b. "Anthropology is the Ethnography of Philosophy: Philosophy is the Ethnography of Itself". Revista Conexóes Parciais 1(1): sem páginas.

2012. "Automodelagem: o lugar da invenção". Revista de antropologia 54(2): 921-953.

ZEA, Evelyn. 2010. "Sobre a ilusão de ter: reflexões antropológicas". Ilha. Revista de Antropologia 12(1/2): 85-102. 


\section{Roy Wagner e a fractalidade: considerações sobre o gesto êmico}

\section{RESUMO}

Com base em uma leitura detida de "A pessoa fractal", de Roy Wagner, pretende-se pensar a questão da nomeação da diferença e sua vinculação ao gesto êmico na antropologia. A partir da proposta de fractalidade wagneriana, coloca-se em pauta uma questão de ordem filosófico-metodológica: como fundamentar a ideia de uma conceitualização nativa circunscrita por um nome? Para enfrentá-la, o texto a seguir acompanha o tratamento dado por Wagner à nomeação, à moeda e à liderança melanésias e argumenta que para aceitar o suposto da instanciação e retenção de escala fractal seria preciso abrir mão da diferença no interior da diferença.

PALAVRAS-CHAVE: Roy Wagner; fractalidade; nomeação; gesto êmico.

\section{Roy Wagner and Fractality: Notes on the Emic Gesture}

\section{ABSTRACT}

Through a close reading of Roy Wagner's "The Fractal Person," this paper dwells on the naming of difference and its relation to the emic gesture in anthropology. A philosophical and methodological issue is posed in relation to the author's approach to fractality: What would be the grounds for the idea of a native conceptualization circumscribed by a name? In dealing with this issue, the text follows the Wagnerian approach to Melanesian naming, currency, and leadership and argues that in order to accept the supposition of fractal scale retention and instantiation it would be necessary to do without difference within difference.

KEYWORDS:Roy Wagner; fractality; naming; emic gesture. 